\title{
Escuela de Pensamiento Libre. Un Viaje Desde el Estigma de la Subnormalidad Hasta el Empoderamiento de Personas Entre Personas
}

\author{
Chema Sánchez Alcón ${ }^{1}$ \\ Generalitat Valenciana - Espanha
}

\begin{abstract}
Resumen
¿Es posible que exista una "escuela" donde se "piense" con "libertad" y cuyos "maestros" sean personas con "discapacidad intelectual"? Estamos hablando de la posibilidad de que personas que han "fracasado" "escolarmente", ya adultos, funden un espacio escolar alternativo a la enseñanza académica dirigido por ellos (con los apoyos necesarios) y donde ellos sean los "maestros socráticos" y las enseñanzas que aquí se imparten, que ellos imparten, tengan que ver con el pensamiento, los valores o las emociones. Y ese sueño es una utopía posible de dos educadores, Chema Sánchez y Juan Carlos Morcillo, y de una institución apoyándolos como FEAPS- Plena Inclusión, junto a Filosofía para Niños-Comunidad Valenciana (FpN-CV) como asesora pedagógica: una utopía posible, un espacio donde las personas no sean etiquetadas por sus deficiencias sino por sus potencialidades, un espacio creativo donde el pensamiento, como decía Ortega, sea una función vital, como respirar o como alimentarse, un espacio afectivo donde las personas sean el centro de nuestras miradas y sus ideas o sueños o valores compongan las materias "troncales" del programa educativo, un espacio inestable donde crezcamos juntos en deberes y en derechos, un espacio libertario que irradie una nueva forma de educar que no se fije en lo que sabemos sino en lo que queremos y en lo que deseamos, un espacio sin copyright cuyo mejor destino es ser copiado, reproducido, recreado en otros lugares donde otras personas con discapacidad decidan tomar las riendas de la educación y demostrarle a la sociedad que no existen "personas discapacitadas" sino que existen sociedades que discriminan o marginan a los demás en función de determinados estandares sociales que, por cierto, no tienen cabida en nuestra Escuela de Pensamiento Libre.
\end{abstract}

Palabras clave: escuela; libertad; pensamiento; discapacidad; igualdad.

\section{Free Thought SCHOOL, A Journey Since THE ESTIGMA OF SUbNORMALITY UNTIL THE EMPOWERMENT OF PEOPLE IN BETWEEN PEOPLE}

\begin{abstract}
There may be a school where they "think" freely and whose teachers are people with intellectual disabilities? We are talking about the possibility of people who have "failed" "academically", as adults, merge an alternative school space runned by them (with the necessary support) and where they are the "Socratic teacher" and the lessons taught there have to do with thinking, values or emotions. That dream is a possible utopia of two educators, Chema Sanchez and Juan Carlos Morcillo, and of an institution to support them as FEAPS - Plena Inlcusión, with Philosophy to Children - Valenciana Comunity (FpN$\mathrm{CV}$ ) as pedagogical adviser: a possible utopia, a space where people will not be labeled for their shortcomings but for their potential, a creative space where thought, as Ortega said, is a vital function such as breathing or eating, an emotional space where people are the
\end{abstract}

\footnotetext{
${ }^{1}$ E-mail: radiofonista99@gmail.com
} 
escuela de pensamiento libre. un viaje desde el estigma de la subnormalidad hasta el

empoderamiento de personas entre personas

center of our looks and these people's ideas or dreams or values compose the "core" materials for the educational program, an unstable space where we grow together in duties and rights, a libertarian space that radiate a new form of education that is not fixed on what we know but in what we want and what we desire, without copyright and whose ultimate destination is to be copied, reproduced, recreated in other spaces where people with disabilities choose to take charge of education and prove to society that "disabled people" do not exist, it is the societies that discriminate or marginalize others based on certain social standard which, certainly, have no place in our School of Free Thought.

Keywords: school; freedom; thinking; disability; equality.

\title{
EsCola de PENSAMENTO LIVRE. UMA VIAJEM DESDE O ESTIGMA DA SUBNORMALIDADE ATÉ O EMPODERAMENTo de Pessoas ENTRE Pessoas
}

\begin{abstract}
Resumo
É possível que exista uma "escola" onde se "pense" com "liberdade" e cujos "professores" sejam pessoas com "incapacidade intelectual"? Estamos falando da possibilidade de que pessoas que tem "fracassado" "escolarmente", já adultos, fundam um espaço escolar alternativo ao ensino acadêmico dirigido por eles (com os apoios necessários) e onde eles sejam os "professores socráticos" e os ensinamentos que aqui se transmite, que eles transmitem, tenham a ver com o pensamento, os valores ou as emoções. E esse sonho é uma utopia possível de dois educadores, Chema Sánchez e Juan Carlos Morcillo, e de uma instituição apoiando-os como FEAPS- Plena Inclusão, junto a Filosofia para CriançasComunidade Valenciana (FpN-CV) como assessora pedagógica: uma utopia possível, um espaço onde as pessoas não sejam etiquetadas por suas deficiências mas por suas potencialidades, um espaço criativo onde o pensamento, como dizia Ortega, seja uma função vital, como respirar ou como alimentar-se, um espaço afetivo onde as pessoas sejam o centro de nossos olhares e suas ideais ou sonhos ou valores componham as matérias "troncais" do programa educativo, um espaço instável onde possamos crescer juntos em deveres e em direitos, um espaço libertário que irradie uma nova forma de educar que não se fixe no que sabemos mas no que queremos e no que desejamos, um espaço sem copyright cujo melhor destino é ser copiado, reproduzido, recriado em outros lugares onde outras pessoas com incapacidade decidam tomar as rédeas da educação e demostrar a sociedade que não existem "pessoas incapazes" mas que existem sociedades que descriminam ou marginalizam aos demais em função de determinados padrões sociais que, por certo, não tem espaço em nossa Escola de Pensamento Livre.
\end{abstract}

Palavras-chave: escola; liberdade; pensamento; incapacidade; igualdade. 
Escuela de Pensamiento Libre. Un Viaje Desde El Estigma de LA SubNORMALidAd Hasta el Empoderamiento de PERSONAs ENTRE PERSONAS

\section{El otro como idiota}

Hace doscientos años, en 1801, un prestigioso médico francés, Philippe Pinel, escribió un tratado decisivo para la clasificación de las "enfermedades" mentales y el nacimiento de la moderna psiquiatría, el Traité Medico Philosophique sur l'alienation mentale. En esa obra calificaba como "alienaciones" estos trastornos. Las personas eran unos "alienados", los médicos se denominaban "alienistas" y la clasificación de las “alienaciones mentales" era como sigue: melancolía, manía, demencia e idiocia. Nos interesa en particular la "idiocia" porque ha sido este el nombre con el que pasaron a la ausencia de historia las personas con "discapacidad intelectual". Su definición de idiocia era la siguiente: perturbación total de las funciones intelectuales. El otrora bobo ahora era un idiota, término tomado del idiotes griego, el que no participa en la polis, en la vida pública. Curiosa red de significantes y significados que consigue su propósito: anular la mente de una persona y su participación como ciudadano en la sociedad. Doscientos años después las cosas han cambiado pero ¿han cambiado lo suficiente?

Volvamos de nuevo a la figura de Pinel (1998). Todos los libros de historia tienen como referencia una fecha imprescindible para entender nuestro tiempo. Somos hijos lejanos de la civilización griega, del Renacimiento, de la tradición judeocristiana pero sobre todo somos hijos de la Ilustración y de la Revolución Francesa. Un 14 de Julio del año 1789, el pueblo de París liberaba la cárcel de la Bastilla y con esa liberación y los disparos a los relojes de París los revolucionarios pararon el tiempo y comenzaron un nuevo régimen, contrario al antiguo, más allá de la sociedad estamental. Es cierto que luego llegó el Terror y el despotismo napoleónico pero las nuevas ideas, la libertad, igualdad y fraternidad, los ideales, los derechos humanos, la ciencia, el progreso y la modernidad habían plantado su semilla en la historia. Los filósofos ilustrados entronizaron a la diosa Razón frente al oscurantismos medieval y las luces iluminaron las sombras. Al menos, esta es la venta del producto. Como bien dice Walter Benjamin, todo documento de 
escuela de pensamiento libre. un viaje desde el estigma de la subnormalidad hasta el empoderamiento de personas entre personas

civilización es a la vez un documento de barbarie. Al igual que en nombre de Dios se han cometido aberraciones, la sacrosanta Ciencia iba a partir de ahora a tomar las riendas del destino de miles de seres humanos en nombre del progreso, en nombre de la verdad, del saber. El poder absoluto de los monarcas, de los nobles y del clero se había desterrado y una nueva casta de sacerdotes con batas blancas, médicos, alienistas, higienistas o incluso científicos se había aupado como los detentadores de la diosa Verdad. Una verdad que, como bien nos muestra en sus obras Michel Foucault, no es más que otra cara del poder, en este caso, un poder concreto, difuminado, un poder micro, pequeño, la "microfísica del poder". En este contexto, un médico como Pinel será un dios viviente, como los grandes médicos directores de manicomios, figuras emblemáticas de los espacios concentracionarios en los que derivó el Gran Encierro, el masivo encierro que sufrieron los bobos, ahora idiotas, un encierro en el que han permanecido hasta la actualidad, en aquellos años para curarlos y en estos tiempos para asistirlos. Pinel realizó solo un año después de la toma de la Bastilla el otro gesto "revolucionario" que, aunque poco conocido, ha pasado a la historia como el Gran Gesto, la retirada de las cadenas que ataban a los locos peligrosos a las paredes de las cárceles o establecimientos para su custodia. En el asilo de La Bicétre y sobre todo del gran manicomio francés, La Salpêtrière, presentó su gesto como la "liberación" de las cadenas opresivas. Al igual que el buenista Guillotin inventó aquel humano artificio para evitar el dolor y humanizar las ejecuciones, el buenista Pinel liberó a dementes e idiotas de las cadenas con el loable objetivo de curarlos, clasificarlos e internarlos en centros alejados de la sociedad. Una sociedad burguesa, ilustrada y racional no podía permitirse tener en su seno a pobres, a mendigos, a locos o a idiotas pululando por sus calles. La psiquiatría moderna no nació con el humano propósito de conocer la verdad de esas mentes diferentes sino con el deseo de apartarlas de la normalidad para, paradójicamente, "normalizarlas" en contextos de encierro y exclusión. De hecho, estos asilos o manicomios nacen con un sano propósito: sanear el cuerpo social de esas irracionalidades; una cuestión elemental de "higiene" física y mental. Es por ello por lo que mendigos, prostitutas o pobres son retirados de las calles por un Cuerpo de "Higienistas" del Estado Francés, una 
nueva clase funcionarial así denominada. Parece el calificativo sacado de una novela de ciencia ficción, pero no, ese cuerpo existió; la realidad suele ser siempre más aterradora. El bobo medieval es ahora un ser irracional que tiene perturbadas las funciones mentales y que debe someterse a un "tratamiento moral" para poder usar la razón. Esa expresión, "no tiene uso de razón” es propia de la mentalidad de una época racionalista que consideró a esta nueva diosa la fuente de todas las luces. Una expresión que sigue utilizándose con profusión en las sentencias judiciales de la actualidad a la hora de incapacitar a las personas con "discapacidad intelectual".

El "tratamiento moral" fue la estrella de los tratamientos humanistas tanto por Pinel como por su discípulo, Esquirol (2011), tan influyente como él o incluso más. La teoría era sencilla: dado que los problemas mentales son un desorden de las pasiones entendidas como "vicios", el resultado de ese desorden es la locura o la misma idiocia. Junto a los baños, curas de hambre, jaulas o castigos (que se incrementan mucho más a pesar de la liberación de las cadenas) es necesario volver a reprogramar el cerebro con una anulación total de lo que hoy podemos denominar el "mundo emocional" de las personas. No es extraño que con el paso de los siglos muchas personas crean que las personas con discapacidad carecen de sentimientos o de afectos.

Los clasificadores de patologías, a modo de botánicos, fueron perfilando poco a poco los tipos de idiocia llegando a elaborarse una de las que más ha permanecido en la historia del estigma: la "normalidad" y la "anormalidad" (después, "sub-normalidad") estando esta configurada por tres categorías: la debilidad mental, la imbecilidad y la idiocia, de menor a mayor gravedad. El responsable de la misma, el gran Esquirol (2011) en su definitiva clasificación o “nosografía filosófica" establecida en su Tratado de las enajenaciones mentales. Si el gran Esquirol (2011) levantase hoy la cabeza y viese cuál es la utilidad que la Escuela de Pensamiento Libre va a dar a la Filosofía no daría crédito posiblemente a lo que estamos haciendo.

Con el paso de los años surge la necesidad de, en el ámbito educativo, crear sistemas universales de enseñanza que desarrollaran los valores ilustrados. Los 
escuela de pensamiento libre. un viaje desde el estigma de la subnormalidad hasta el empoderamiento de personas entre personas

sistemas de instrucción pública se organizan y deben dar cabida a ese nuevo derecho a la escolarización surgido de las tradiciones liberales. Una conquista que, en el caso de la intrahistoria de las personas con discapacidad, es otro motivo para la discriminación. Dado que no "todos" los seres humanos son iguales y en la escuela deben ser aceptados los niños "normales" se idean sistemas de clasificación que impidan que los idiotas e imbéciles no puedan acudir a las aulas. Es el nacimiento de las teorías de la inteligencia aplicadas a la escuela. Binet, que ya estaba investigando sobre esta nueva noción, la "inteligencia", es invitado por el gobierno francés para implementar esos sistemas de medición cuya finalidad era la detección de "anormales" para evitar su ingreso en los sistemas públicos de escolarización y, en teoría, dedicarles una atención "especial". Corrían los años 90 del siglo XIX y el gobierno quería escolarizar a todos los niños entre los 6 y 14 años de edad. Binet y otros expertos fueron avisados para formar parte de una Comisión Gubernamental para el "estudio de niños retardados". Pero cómo detectar ese "retraso". Binet no quería utilizar métodos físicos de detección de idiotas como la frenología o medición de protuberancias en las cabezas. Huyendo de estos métodos idea otros métodos nuevos, "psicológicos" que midan el rendimiento "mental" de los niños: bienvenidos a los primeros test de inteligencia y sus secuelas nefastas para la discapacidad a lo largo del siglo XX. El Test de Rendimiento Escolar de Binet pasa a la historia como uno de los primeros logros de la psicología moderna y de su nueva especialidad científica: la psicometría. En el año 1903, su libro Estudios experimentales sobre la inteligencia, abrirá las puertas a un nuevo mundo de exploraciones mentales. Junto con su discípulo Simon elabora la primera escala de inteligencia y define el concepto "edad mental", un constructo cuyo éxito será fulminante. Binet, otro buenista, no pretendía con sus herramientas etiquetar a los niños; más bien al contrario, era un afán humanitario lo que perseguía pero, otra vez más, el resultado de esta historia es muy diferente ya que sus test se utilizaron como arma arrojadiza para seleccionar y marginar. El resto de la historia ya es parte de la psicología moderna. Terman, en Estados Unidos, implica en todo este proceso a la Universidad de Stanford que elabora la primera escala con validez mundial, la Escala Stanford-Binet. Son años de euforia 
intelectual en los que se cree haber encontrado la clave, el Factor G, o inteligencia general, una cualidad física, como el color de ojos o la altura que puede se medida utilizando los procedimientos científicos. La psicología ya no es una disciplina cualquiera sino una ciencia más entre las ciencias. La diosa Razón sigue su curso a lo largo de la historia. Las virtudes de los test eran casi mágicas y se comenzaron a aplicar no sólo a niños sino a inmigrantes, a indios o a negros quedando demostrado con resultados "científicos" que la raza blanca era "superior" en inteligencia a otras razas.

\section{Del lenguaje de los retrasos al lenguaje de los apoyos.}

El modelo de déficit descrito en el apartado anterior ha llegado hasta nuestros días y utiliza el Coeficiente de Inteligencia (CI) como manera de clasificar dividiendo a las personas con "discapacidad intelectual" en límite, ligero, medio, severo y profundo. Es solo a partir de los años 90 cuando la AAMR, la Asociación Americana para el Retraso Mental (referencia mundial en la materia) cambia el paradigma y procede a una nueva concepción de la discapacidad tomando como base no tanto lo que no se tiene, la carencia de inteligencia, como lo que se necesita, a saber, los apoyos. Así, el modelo pasa a ser un modelo social inclusivo donde conceptos como bienestar y sobre todo calidad de vida y autodeterminación son una nueva manera de enfocar las intervenciones socioeducativas. La nueva clasificación no se centra tanto en el CI sino en la intensidad de los apoyos que se necesitan y que pasan a clasificarse en cuatro tipos: intensidad intermitente (episódica, ocasional, de corta duración, permanente pero no continuada en el tiempo) limitada (mayor tiempo pero quizá no tanta intensidad, menos personas de apoyo), extensa (regular y sin limitación temporal) y generalizada (constante, intensidad elevada, mas personas de apoyo).

En el nuevo modelo se resalta el objetivo prioritario de la autonomía que podría derivar o no en independencia y autodeterminación, la utopía posible de los nuevos movimientos de autogestión entre los que se encuentra nuestra escuela, la Escuela de Pensamiento Libre. El actual modelo es considerado un modelo funcional de la discapacidad donde se integran esa dialéctica necesaria entre 
escuela de pensamiento libre. un viaje desde el estigma de la subnormalidad hasta el empoderamiento de personas entre personas

capacidades y funcionamientos.

Durante mucho tiempo, la discapacidad ha sido considerada en términos negativos, como patología, aberración, y como algo atípico. la gente discapacitada era considerada, de alguna manera, como enferma, rota o necesitada de arreglo. Hacia finales del siglo XX, estos conceptos empezaron a ser reemplazados por otros modos de pensar sobre la discapacidad; estaban centrados en considerar ésta como una función de la interacción entre capacidad personal y el contexto en el cual las personas con discapacidad vivían, aprendían, trabajaban y jugaban. Dos de los llamados modelos funcionales de discapacidad se pueden ver en la Clasificación internacional de funcionamiento, discapacidad y salud (CIF) de la Organización Mundial de la Salud (OMS) y el sistema de clasificación de 1992 de la Asociación Americana de Discapacidades Intelectuales y en el desarrollo (AADID) (...) La discapacidad no es algo que una persona tiene o algo que es una característica de la persona, sino que, en su lugar, es un estado de funcionamiento. (WEHMEYER, 2009)

Este modelo "funcional" es en sí mismo "revolucionario" y creo que sus consecuencias no han sido todavía entendidas por la población o por algunos profesionales. La persona con discapacidad, en realidad, tiene limitados los funcionamientos (adaptativos o de su inteligencia o tiene algunas enfermedades asociadas) pero la persona, como tal persona, no tiene discapacidad; son sus “estados", sus "funciones" las que están limitadas; la "discapacidad de la persona" es una cuestión social que debe ser modificada y por ello el modelo social inclusivo trata de erradicar esta confusión y ser consecuente tratando a la "persona" como "capaz" y explorando esas capacidades con los apoyos y los accesos. Si los profesionales al crear los programas siguen hablando de "personas deficientes" las intervenciones irán en una línea y si entienden que son personas o ciudadanos con limitaciones irán en otra línea. La preposición es circunstancial. Todo esto desemboca en lo que el mismo Wehmeyer y Turnbull denominan las "practicas inclusivas de tercera generación".

Partiendo de estos presupuestos y de este paradigma actual y futuro de la discapacidad hemos inventado la Escuela de Pensamiento Libre y las escuelas de diálogo que le dan sentido y significado a este modelo social e inclusivo.

\section{Breve historia de otra escuela posible: la Escuela de Pensamiento Libre.}

EL Escuela Pensamiento Libre es un proyecto que nace el año 2008 en un Encuentro de Autogestores, personas con "discapacidad intelectual” que se reúnen 
una vez al año para hablar sobre su mundo y su realidad. En aquel año, el responsable del programa, Juan Carlos Morcillo y el profesor de Filosofía Chema Sánchez presentaron un programa de pensamiento basado en la Metodología Lipman cuyo objetivo era formar a personas de apoyo y a personas con discapacidad en habilidades cognitivas y de autodeterminación.

Trabajar estas habilidades y destrezas educativas en personas con un historial de "fracaso" escolar suponía y sigue suponiendo un reto en cuanto federación. Nuestra propuesta era y sigue siendo no seguir incidiendo en ese fracaso sino explorar una vía alternativa para trabajar con el potencial cognitivo de personas con limitaciones intelectuales pero a la vez con muchas posibilidades de aprendizajes apenas explorados. Aprender a pensar, expresar emociones o descubrir nuestros valores eran objetivos que considerábamos necesario abordar desde una perspectiva crítica, creativa y cuidadosa.

Durante varios años, doce centros ocupacionales de la Comunidad Valenciana coordinados por FEAPS-Plena Inclusión pusieron en marcha el "programa de pensamiento libre" dentro de sus respectivos horarios. Las personas de apoyo, de una manera periódica, se reunían en sesiones de trabajo con el profesor Chema Sánchez para expresar dudas, practicar la metodología utilizada y en general para poner en común lo que los usuarios iban realizando en sus sesiones de trabajo. Al final del proceso formativo muchos centros presentaron los “diarios" realizados por los usuarios, diarios en los que reflejaban sus ideas, sentimientos, valores...

La experiencia y el programa completo fue editado por el profesor Chema Sánchez en el año 2010 en un libro editado por una de las editoriales de prestigio del país, la editorial Pirámide, especializada en psicología y pedagogía. Su título es ya significativo: Pensamiento libre para personas con discapacidad intelectual. Esta obra es una de las bases metodológicas para desarrollar el trabajo del proyecto.

Pues bien, el año 2013 FEAPS-Comunidad Valenciana da un paso más en esta línea de empoderar y darle protagonismo real e intelectual a las personas con discapacidad y se propone, en el contexto de los grupos de autogestores, formar a las mismas personas con discapacidad en esas habilidades cognitivas para que a su 
vez, en un futuro, sean ellos los que formen a otras personas. El sueño final, la utopía posible en la que ahora estamos embarcados es la creación de una red de escuelas alternativas de pensamiento libre donde los "profesores" (a los que denominamos "maestros socráticos") sean las mismas personas con discapacidad y los contenidos educativos de la escuela fueran impartidos por ellos mismos tomando como punto de partida una metodología activa, democrática y creativa como es la Metodología Lipman, base pedagógica de este proyecto en el que ellos participan como sujetos activos de un aprendizaje que deben luego aplicar por ellos mismos.

Es aquí, en las bases pedagógicas del proyecto, donde tiene un papel fundamental la Asociación de Filosofía para Niños de la Comunidad Valenciana (FpN-CV) que participa activamente en la configuración de los contenidos de la red de Escuelas de Diálogo aportando su experiencia educativa y los formadores de FpN.

Estamos convencidos desde FEAPS-Plena Inclusión Comunidad Valenciana y desde FpN-CV que si trabajamos los potenciales de aprendizaje de las personas y los procesos de pensamiento más que los contenidos concretos predeterminados podemos abrir una vía alternativa, posible y a la vez utópica para darle forma a este pequeño sueño de "otra escuela posible" en la que personas etiquetadas de "deficientes" sean los protagonistas de esa institución inclusiva y diferente. Esta idea de "empoderamiento educativo" se concreta, pues, en este proyecto que juega con ese derecho a soñar que debiera ser uno de los derechos humanos fundamentales. Entendemos, asimismo, que existen muchas maneras diferentes de educar, pero educar desde la diferencia, desde la diversidad y desde las posibilidades abiertas a la inclusión de personas que tienen mucho que decir, aparte de un sueño y de una utopía, debe ser una obligación para nuestras instituciones, empeñadas en defender el valor y la dignidad de seres humanos a los que siempre hemos mirado desde sus defectos más que desde sus potenciales.

El otro como persona entre personas. A vueltas con la nueva etiqueta: (dis) capacidad intelectual. 
En nuestra Escuela esta expresión que la comunidad internacional lleva utilizando desde hace unos años, carece de sentido. Antes de esta expresión existieron otras (idiocia, retraso mental, subnormalidad) cuya carga estigmatizante es todavía mayor. A la espera de que esa comunidad internacional adopte un lenguaje aún más inclusivo consideramos que todas las personas poseen capacidad y a la vez incapacidades. Poner un paréntesis para recordarlo es sólo un gesto simbólico, pero denota esa preferencia que tenemos en la Escuela por la complejidad del ser humano. Entre nosotros no existen problemas al reconocer que algunas personas poseen limitaciones cognitivas y que necesitan apoyos. No reconocerlo sería una ingenuidad. $\mathrm{Y}$ estas personas, los protagonistas del aprendizaje, son personas en primer lugar y después con "(dis)capacidad". En el día a día de la Escuela, toda la metodología está orientada a buscar aquello humano que nos identifica a todos como seres iguales y libres dispuestos a aprender en comunidades de indagación y practicando la ayuda mutua, pero al igual que en el caso de hombres y mujeres, blancos y negros, indígenas $\mathrm{u}$ homosexuales necesitamos encontrar una identidad gramatical que, desde esa diferencia, persiga la igualdad. Algunas personas, querámoslo o no, han tenido en su vida anomalías de tipo neurológico o cromosómico y los efectos de tales anomalías se concretan en esas limitaciones. Partimos de un hecho, pero este hecho es solo eso, un punto de partida, nunca de llegada y ni siquiera es un punto del camino. Pero sí es un punto de partida. En la lotería cerebral existen personas que, a lo largo de su vida, nos guste o no, tendrán unos niveles de abstracción y de inteligencia moderados. Ellos comienzan el juego con una clara desventaja. Esta desventaja es evidente y no es solo pura diferencia o diversidad, sino que es una desventaja clara y patente. Un niño o niña que nace niña no tiene esta desventaja; tiene una diferencia de género a través de la cual podrá ser, en el proceso de su vida, discriminada o no. En cambio, una niña con Síndrome de Down nace ya con una desventaja porque sus cromosomas son irregulares, no está dentro del comportamiento habitual de los cromosomas. El color de la piel no es un fruto de una irregularidad cromosómica (en el siglo XIX sí se consideró como una anomalía). La trisomía del cromosoma 21 o que un cerebro pueda nacer sin 
escuela de pensamiento libre. un viaje desde el estigma de la subnormalidad hasta el empoderamiento de personas entre personas

oxígeno y ello cause un deterioro cognitivo irreversible sí son anomalías que provocan un efecto al que denominamos "desventaja" inicial y al que le podemos el nombre "discapacidad". Los movimientos de defensa de las personas con discapacidad que niegan incluso el punto de partida de la discapacidad son movimientos que ponen el acento en la diferencia o diversidad, pero algunos de ellos llevan esta diversidad hasta el mismo punto de partida negando en todo momento que esa diferencia sea una limitación. Nos parece excesiva esta defensa de la diferencia por la diferencia. Al igual que en los movimientos feministas existe un "feminismo de la diferencia" frente a otro de la "igualdad" podríamos hablar de una "discapacidad de la diferencia" y otra de la "discapacidad de la igualdad". En nuestro caso, la Escuela de Pensamiento Libre, no niega esa desventaja; más bien al contrario, al reconocerla, esa desventaja juega a nuestro favor en tanto se convierte en oportunidad de superación. Esto implica también una filosofía de los "límites" entrelazada con una filosofía de las "capacidades". Decirle a alguien con necesidad de apoyos que "todo aquello que pueda pensar es posible" nos parece una ingenuidad e incluso diría una falta de respeto. Tampoco a alguien sin esa desventaja deberíamos decirle algo así. A nosotros nos gusta decir: tú eres un ser lleno de posibilidades y podemos explorarlas juntos. Estar lleno de posibilidades o potencialidades como también nos gusta decir no es lo mismo que invitar al idealismo más desencarnado que a veces tiene el nombre de "independencia" absoluta. Al igual que no es posible la libertad absoluta tampoco es posible la independencia absoluta. Somos, todos y cada uno de nosotros, en tanto seres humanos, seres limitados y frágiles e interdependientes. La paloma vuela, decía Kant, porque supera el limite de la resistencia del aire; en un cielo sin resistencia, en medio del vacío, no podría volar. No renunciamos en ningún momento al lenguaje de los apoyos que, sin duda, nos parece mucho más humano y conectado con el otro que el lenguaje de la carencia de vínculos. La libertad, es cierto, puede entenderse como independencia, pero nosotros queremos entenderla como participación activa en la sociedad en la cual vivimos para transformarla. Quizá el sueño de la independencia sólo pueda ser disfrutado por Robinson Crusoe en su isla desierta, justo antes de encontrarse al indígena Viernes y tratar de adoctrinarlo. 
Si el término "(dis) capacidad" puede ser analizado de esta manera, unirlo al calificativo "intelectual" nos parece un sin sentido que no hace sino remarcar, con un eufemismo, el mismo calificativo anterior; aquel "mental" (aplicado al retraso) es el mismo de ahora, "intelectual" (aplicado a discapacidad). Incluso peor; si la "mente" como un todo fue objeto de retraso en la anterior acepción, en este caso cualquier capacidad intelectual ha sido anulada por el sustantivo discapacitante. La RAE define el adjetivo latino "intellectualis" como "perteneciente o relativo al entendimiento". Y el "entendimiento" es tanto la "razón humana" (tercera acepción de la RAE) como una "potencia del alma" en virtud de la cual alguien “concibe las cosas, las compara, las juzga, e induce y deduce otras de las que ya conoce". A saber, tener discapacidad intelectual es como decir que un ser no está dotado de "racionalidad". O que, en la misma terminología medieval y teológica del diccionario, carece de las tres potencias del alma, el entendimiento, la memoria y la voluntad. Y todo ello no es baladí porque al anular ese tradicional "uso de razón", eliminamos también la "capacidad" civil de las personas. La razón, entendida, como un todo es el intelecto, el entendimiento, es decir, la inteligencia. En sentido estricto, la limitación de las personas se refiere justo a esto, a la "inteligencia" entendida de una determinada manera, una inteligencia basada en niveles de abstracción y en resolución de problemas para los que es necesario poseer esos niveles de abstracción. Pero la "racionalidad" humana, decimos, es mucho más que inteligencia abstracta; la racionalidad humana entendida como la entienden muchos filósofos en la actualidad es una red compleja de relaciones en la que habita no solo la lógica abstracta sino la lógica informal, el pensamiento divergente, la creatividad, el lenguaje, las emociones o los valores. Todo ello es facultad humana y "potencias" (en el sentido de potenciales) del alma (es decir, del espíritu humano). Todo ello es, por tanto, intelectual.

En la Escuela de Pensamiento Libre, indignados con ese estigma gramatical, hemos elaborado todo un plan pedagógico y humano basado precisamente en la demostración práctica de que las personas con "limitaciones de la inteligencia abstracta" están dotadas de facultades "intelectuales" inexploradas y que tienen que ver con todo aquello que no es medible de una manera cuantitativa, esas 
facultades o potenciales son los "horizontes pedagógicos" en los que se mueven las personas, esos horizontes están impregnados de una "racionalidad cordial" (Cortina, 2006) y nos hablan de la medida humana del mundo, nos hablan de la lógica de la vida, de los sentimientos con los cuales atrapamos el mundo, de los valores éticos expresados en deseos y en anhelos de realización personal; esos horizontes son el espacio en el que se desarrolla nuestra mente de una manera vivencial, es el logos (la ratio) compartida, es decir, el dia-logos, la palabra, el argumento (no sólo lógico sino narrativo porque todo argumento es un discurrir relacional de un relato), es la filosofía de la vida, del ser y de la búsqueda de nuestro lugar en el mundo (una filosofía que toma como base no el conocimiento humano sino el dolor del otro); en definitiva, es la Razón entendida como un Logos no clasificatorio (la ratio, en su origen latino, deriva de la clasificación, de la medida, de la proporción) sino como un la "palabra" que nos configura. La racionalidad narrativa de la que hablamos es la de los seres dotados de palabras con las cuales nos comunicamos y filosofamos. He aquí el eje, la clave de nuestra manera de entender la racionalidad en la Escuela de Pensamiento Libre: seres humanos a los cuales la tradición, la educación formal y la sociedad en la que viven les ha arrebatado el logos, las palabra, en un horizonte distinto, en un espacio alternativo donde estamos dispuestos a explorar entre todos las posibilidades del otro, esa palabra cobra todo su esplendor en forma de escucha activa, de toma de conciencia de lo que somos, de búsqueda de la verdad y de la justicia, de reconocimiento, una palabra que no es respuesta a las preguntas del profesor (véase sistema educativo tradicional) sino que es palabra propia, y esa palabra propia tiene la forma de pregunta, de cuestionamiento del mundo, de lectura de la realidad y esa palabra, ese logos con el cual me hago preguntas no es una cesión del que tiene la última palabra sino que es una facultad inalienable que todos poseemos por el hecho de ser seres racionales y libres.

Por tanto, en la Escuela de Pensamiento Libre no existen personas con discapacidad intelectual.

\section{Algunas deudas pedagógicas de la Escuela}


La Escuela de Pensamiento Libre mantiene una deuda impagable con las ideas que nos legó uno de los padres de la pedagogía crítica de nuestros días: Paulo Freire. Veamos en qué consiste esta deuda y esta reconocida influencia.

¿Cómo entiende Freire la educación? Como un acto de compromiso político en el cual una persona no sólo aprende unas letras, sino que aprende a pensar desde la libertad y la dignidad. No se puede enseñar a alguien a leer sin enseñarle a tomar conciencia de su ser y de su estar en el mundo. Cuando hablamos de educación en tanto acción política no nos referimos a ningún tipo de adoctrinamiento ideológico ni partidista sino a esa toma de conciencia en la cual el individuo reflexiona sobre su ciudadanía activa, sobre sus condiciones de vida, sobre lo que es y lo que vive y aquello que desearía tener o conquistar; esa reflexión no es mero conocimiento de una lengua sino la conquista de un nuevo lenguaje, crítico, creativo, un lenguaje donde las palabras nacen de la comunidad y no vienen impuestas por los discursos dominantes.

Con este sistema horizontal en la educación, los seres humanos se sienten “sujetos de su pensar, discutiendo su pensar, su propia visión del mundo, manifestada, implícita o explícitamente, en sus sugerencias y en las de sus compañeros." (FREIRE, 2008) Esto supone que no existe un saber predeterminado en forma de "cartillas" llenas de frases absurdas, sino que las "palabras generadoras" nacen de la propia comunidad donde se está realizando el proceso de alfabetización. Los voluntarios que trabajaban con Freire, pues, vivían un tiempo en la comunidad y tomaban nota de algunas palabras habituales de la comunidad, no más de 40 o 50 términos.

Esta manera de entender el proceso educativo está muy lejos de lo que Freire denomina la "educación bancaria", una manera de educar que presupone que "el educador es el que sabe, los educandos los que no saben; el educador es el que piensa, los educandos los objetos pensados; el educador es el que habla, los educandos los que escuchan dócilmente" (FREIRE, 2008)

El objetivo del proceso educativo es la "la toma de conciencia", en sus términos "concientizar" (concienciar) al alumno de su situación en el mundo y de su capacidad de transformarlo; la educación deviene en un acto político, de 
ciudadanía y de compromiso, es una cuestión de valores y no de "saberes". "Nadie lo sabe todo, nadie lo ignora todo. Todos sabemos algo, todos ignoramos algo." (FREIRE, 2002) Concienciar, como decimos, nada tiene que ver con el adoctrinamiento ideológico ni con el mero partidismo sino con la toma de conciencia de la valía propia en cuanto ciudadano libre y responsable. Concienciar en nuestro caso tiene que ver con aprender a pensar por uno mismo y a descubrir el mundo intelectual del que las personas han sido despojados; de ahí ese nombre todavía dudoso que es "discapacidad intelectual": "Existir es sólo vivir, pensar es difícil, hablar está prohibido." (FREIRE, 1990)

La educación es problematizadora porque plantea problemas, preguntas más que respuestas, porque plantea problemas vitales que son parte de la vida y porque nos ayuda a ser libres.

Una reinvención y a la vez una revolución son nada más y nada menos que el objetivo de Freire que toma como punto de partida el discurso dialéctico de carácter hegeliano de "superación de la contradicción", del encuentro de una "síntesis"; de la superación de la dialéctica amo-esclavo, opresor-oprimido llegando a una relación horizontal en la cual el proceso educativo, al igual que el proceso social, devenga en discurso "revolucionario" : la revolución educativa propuesta por Freire trata de superar esa contradicción. “Decir que los hombres son personas, y como personas son libres, y no hacer nada para lograr concretamente que esta afirmación sea objetiva, es una farsa." (FREIRE, 2008)

Como se puede observar, todos estos principios afectan de una manera radical a nuestros planteamientos pedagógicos en la Escuela de Pensamiento Libre. Exceptuando el objetivo concreto que persigue Freire, tratar de alfabetizar a los adultos. En nuestro caso, en los contextos de personas adultas con discapacidad intelectual, sabemos que existe un alto grado de analfabetismo; las personas adultas de las que hablamos son hijas del fracaso escolar y el acceso a la lectoescritura es básico. En los centros existen programas ya en marcha para desarrollar estas competencias tanto verbales como numéricas. En nuestro programa pedagógico, directamente nos hemos saltado este objetivo manteniendo las ideas esenciales de Freire relacionadas con la educación como una forma de 
liberación de la exclusión a la que sigue estando sometida la persona con discapacidad.

En el campo de la exclusión cognitiva e intelectual este derecho a pensar por uno mismo es el quid de la cuestión porque ya la sociedad presupone en este un retraso, una deficiencia que conlleva una incapacitación, no solo vital sino mental. Y la incapacitación mental es el comienzo de la verdadera opresión y no sólo exclusión. El "oprimido" en el campo de la discapacidad no es la persona que vive bajo unas condiciones dictatoriales encerrado como hace años en las casas o en el manicomio (aquella opresión era evidente) sino que es aquel ciudadano al que se le deja vivir y se le trata incluso de integrar, pero sin atreverse a reconocerlo como igual y como libre. El objetivo final, por tanto, en nuestro caso, no puede ni debe ser la alfabetización sino el aprendizaje de la autodeterminación y el empoderamiento de la persona para que luche y anhele y aprenda a no tener miedo de la libertad. Por eso, la Escuela de Pensamiento Libre es una incitación al aprendizaje reflexivo, a la toma de conciencia de nuestro ser y estar en el mundo, a rescatar las palabras perdidas que otros han dicho por nosotros, no es una invitación imprudente a lanzarse al vacío de la independencia o la libertad entendida como satisfacción inmediata de mis deseos instintivos. Los objetivos de la Escuela persiguen la exigencia de la búsqueda de la autonomía que es, tengamos o no discapacidad, una conquista compleja.

De ahí que, en un tipo de educación así, los programas siempre son "horizontes" en los cuales nos movemos, el norte hacia el cual caminamos, pero los caminos son infinitos. En la Escuela existen algunos guías en ese caminar, algunos "objetivos" generales como la educación de las emociones, o del pensamiento o el trabajo con valores humanos; y sabemos que el método es clave y no podemos limitarnos a realizar sesiones de modelado con personas para hacerlas más educadas, más dóciles o con mejores habilidades sociales. Necesitamos saber porque es consustancial a nuestra metodología que la persona puede decir no y romper hasta estas reglas básicas que buscan su emancipación y su liberación, pero nadie tiene derecho a imponer a otra persona adulta su sentido de la libertad si esa persona no ha decidido por sí misma unirse al grupo para buscar, más allá de la 
soledad, una búsqueda personal e intransferible.

Y en cuanto a metodología, más que hablar de "método" nos gustaría hablar de "condiciones de posibilidad" o de la metodología Lipman pero entendida desde la perspectiva que lo hace el filósofo y pedagogo Walter Kohan y su manera de entender la infancia, una referencia no cronológica a la edad de un infante sino una condición de posibilidad de la experiencia humana "sin importar la edad de la experiencia" (KOHAN, 2004). En este sentido, esta metodología es un ejercicio de exploración de las condiciones de creatividad de la experiencia humana del otro, de su fragilidad, de su pensar alternativo e insólito, un pensar que deviene, intenso, discontinuo, indisciplinado. Como este método no es posible aplicarlo en una escuela tradicional y formal solo nos queda la opción de crear una "escuela popular", una escuela libre a la que hemos denominado Escuela de Pensamiento Libre.

\section{Algunas deudas filosóficas de la Escuela: la fragilidad humana y el dolor del otro.}

El filósofo riojano Rezola Amelivia entiende la filosofía no como un proceso dialéctico a través del cual conocemos esencias o verdades inmutables sino como una praxis, como una forma de "cuidado de la fragilidad humana" (REZOLA, 2013) que configura una "racionalidad narrativa" en la cual se practica el "reconocimiento de todos los seres humanos como protagonistas" del logos, de la ratio. La "razón" no es, pues, un ente inaccesible a la cual acceden sólo unos cuantos privilegiados sino una forma de humanidad que presupone no el saber y la certeza sino la indecisión y el estar perdido, buscando el sentido. Y la única forma de buscarlo, dice Rezola (2013), es interpretar el "sentido del mundo".¿Las personas con discapacidad intelectual tienen acceso al mundo de la filosofía? ¿Son capaces de buscar el sentido del mundo?

$\mathrm{Si}$, como dice Rezola (2013), la filosofía es una "actitud" (y no un saber) que nos instala en la propia "extrañeza del mundo", ellos, los excluidos de la sociedadmundo, al sentirse perdidos y deseosos de buscar, son algunas de las personas con más predisposición filosófica; es por ello por lo que pueden filosofar, no porque sepan o sean "inteligentes" sino porque desean encontrar una salida a su situación 
de excluidos. Si nosotros reconocemos esa actitud estamos en el camino de entender la naturaleza humana de otra manera, incluyendo la fragilidad como idea-fuerza, porque la fragilidad no es la debilidad objetiva del otro sino su fuerza para poder reconstruirse desde sí mismo, desde su imaginación creadora y dotarse de sentido.

La actitud filosófica, dice Rezola (2013), desemboca en un estar abierto a la vida como una forma de "abrazar el mundo", un estar abierto a los "vaivenes del reconocimiento" y, sobre todo, un estar abiertos a los "encuentros con nuestras posibilidades insospechadas".

Solo desde el reconocimiento de esta fragilidad podemos construir posibilidades. No existen criterios objetivos para proclamar las deficiencias de nadie en este nivel de humanidad originaria. La sociedad y sus sacerdotez clasifican y etiquetan, pero la misión del filósofo es desmontar estos ladrillos epistemológicos y estos discursos absolutos para encontrar la "humana medida del mundo".

La Escuela de Pensamiento Libre hace suyas estas ideas y ha tratado de construir todo un programa pedagógico desde esas posibilidades insospechadas a las que nosotros denominamos "potencialidades" y que hemos dividido en cuatro: potencialidades cognitivas, morales, emocionales y filosóficas.

Al igual que el filósofo Rezola (2013) integraba en su teoría de la "racionalidad narrativa" la "fragilidad" humana y el cuidado, otro filósofo actual, Reyes Mate, integra el sufrimiento de las víctimas en ese nuevo paradigma donde la filosofía abandona su pedestal epistemológico y se sitúa al lado de los excluidos y perseguidos por los discursos dominantes.

Nos recuerda Mate (2013), siguiendo la tradición de la teoría crítica de Adorno, que el sufrimiento es condición de toda verdad.

La memoria, así, es una condición epistémica básica y el recuerdo de la barbarie no es un mero recordatorio memorístico sino un principio básico de la teoría. Es cierto que estas teorías se construyeron en torno al holocausto en cuanto barbarie elegida pero la historia está plagada de colectivos que han sido excluidos. Existen colectivos de excluidos privilegiados por la investigación histórica y 
escuela de pensamiento libre. un viaje desde el estigma de la subnormalidad hasta el empoderamiento de personas entre personas

colectivos olvidados. Olvidados, pues, y excluidos.

Las personas con (dis)capacidad intelectual pertenecen a este último conjunto, rizando el rizo del oprobio. No existe ningún memorial de las víctimas de los manicomios en nuestro país ni existe siquiera una relación de personas que en esas instituciones fueron sometidos a torturas, a tratos inhumanos $y$ degradantes. El Holocausto y las guerras tienen incluso sus bajas, algunas ONGs, se preocupan por señalar los presos políticos del mundo, perseguidos de toda índole son apoyados por instituciones internacionales. El pasado poblado de fantasmas de idiotas vegetando en instituciones carcelarias es solo una sombra y el olvido ha abonado la tierra donde yacen.

No queremos sin embargo lamentarnos por esta injusticia histórica, sólo reflejarla y recordadle a los bienpensantes que aquellas cenizas siguen abonando un estigma al que los etiquetadores del mundo han limpiado de agresividad y han bautizado con nuevas políticas sociales donde todas las personas son tratadas con dignidad y atendidas. Y a la vez aniquiladas. Si no fuese así, las personas con (dis)capacidad intelectual serían poseedoras de derechos y serían uno más en nuestras sociedades competitivas y complejas pero esto no es así y aunque ninguna persona en nuestras sociedades democráticas es encerrada en una jaula en instituciones carcelarias, cuantas veces, si escuchamos la verdad del otro, si nos paramos a mirar y a interpretar las palabras del otro comprendemos que no siempre las jaulas son visibles y que el inconsciente de todos ellos está fraguado sobre ese sufrimiento inveterado, un sufrimiento que a veces es una segunda piel y que no siempre es fácil sacar a la luz. Es como si las historias de esos otros que existieron fueran parte de la propia historia individual.

En este sentido, es necesario incorporar como categoría conceptual ese "sufrimiento" para poder ver y tratar a las personas que ahora siguen vinculadas a la pena y a la caridad de los normales. "El sufrimiento es condición de toda verdad." (MATE, 2001) La memoria deriva, pues, en un imperativo ético del cual no debemos desligarnos, el "imperativo anamnético" que Mate propugna: que el sufrimiento del otro sea para ti un horizonte para comprenderlo y para reconocerlo no solo como ser humano (una obviedad) sino como ser humano libre, pensante, 
racional, moral, un interlocutor válido desde sus limitaciones. Y a partir de este reconocimiento, comenzar a andar juntos, a construir un camino juntos: "Las víctimas sobre las que se ha construido la historia, tantos siglos invisibilizadas y de tantas maneras privadas de significación, son las piedras descartadas. Parecería haber llegado el momento de construir sobre ellas. Falsa alarma. La historia sigue a su aire atraída por el seductor encanto del progreso. Hay que seguir cepillando la historia a contrapelo" (MATE, 2013)

Una teoría anamnética de la justicia supone una cierta desvinculación del discurso clásico de la modernidad y de la ilustración que relaciona de una manera causal responsablidad, libertad y autonomía. Solo somos responsables si somos libres y somos libres si somos autónomos. No podemos, por ejemplo, ser responsables de lo que no hemos hecho. El olvido de la barbarie es una de las consecuencias de este nuevo estado de la cuestión. Y, claro está, la exclusión de aquellos seres que no cumplen con el modelo de racionalidad ilustrada, en este caso, personas que tienen mermada su autonomía e independencia. Una ética basada en la independencia como conditio sine qua nom de la libertad y de la responsabilidad conduce a la exclusión del discurso dominante de muchos seres humanos (y no humanos) que han sido objeto de humillaciones históricas.

Es necesario que la verdad tenga en cuenta el dolor de las víctimas pero también que tenga en cuenta una visión de la naturaleza humana diferente, una visión menos racionalista del mundo, una visión más “integral” e integrada del ser y una visión más "interdependiente" de la razón. Autonomía, libertad o responsabilidad como parte de un discurso donde no falte la "com-pasión", el pathos compartido que es el sufrimiento y el "reconocimiento de la alteridad", del otro en cuanto otro que soy a la vez yo, una otredad que no desemboca en la diferencia sino que la tiene en cuenta porque el camino a recorrer, el fin último, el horizonte narrativo donde todos contamos no es un camino de diferencia sino de comun-idad, de comun-ión en cuanto aceptación de la igualdad esencial de los seres humanos.

Algunos autores del siglo XX (Levinas, Benjamin, Rosenzweig) han 
considerado que la historia del logos en cuento razón moderna es una especie de "ontología de la guerra" ya que se ha reducido la pluralidad y la diversidad del mundo a una unidad esencial construida sobre las bases de un individuo libre, autónomo y responsable. Una unidad lógica sin diversidad y sin diferencias y sin emociones y sin vísceras y sin imperfección. Quizá aquellos sones platónicos de las ideas perfectas en un universo ideal siguen sonando en nuestros discursos de dominación.

El ser humano deviene sujeto moral no en cuanto ser racional y libre sino en cuanto ser humano responsable del otro. La otredad aquí es necesaria. Solo si hay otros hay individuo lo cual no implica la disolución del yo sino la consideración de que somos seres responsables solo si somos seres interdependientes.

Nuestro proyecto pedagógico, la Escuela de Pensamiento Libre, no habla en el lenguaje todopoderoso de la Independencia, de la Autodeterminación, de la Responsabilidad o de la Libertad sino del "aprendizaje de" todas esos horizontes narrativos hacia los cuales tendemos. Nos reconocemos, sí, como seres libres e iguales, pero nos reconocemos también como seres frágiles y seres perdidos y seres dolientes que buscan una salida junto a los otros, en comunidad de diálogo, una comunidad a la que nosostros denominamos "comunidad cordial de conversadores perplejos". Hablamos en el lenguaje de los apoyos porque es el lenguaje más plenamente humano y queremos, sí, que se reconozcan las "capacidades" que tenemos, pero sin renunciar a nuestras limitaciones y a nuestra discapacidad. Somos seres bifrontes y ansiamos vivir como personas independientes, pero antes ansiamos que nos reconozcan como seres dotados de razones y de emociones. La autodeterminación no es una bandera por la que luchar ni una nación que conquistar ni una meta a la cual tender sino un horizonte $\mathrm{y}$ un camino por el cual queremos transitar. Una vez que lo andemos o desandemos las metas las inventaremos nosotros.

\section{Una Escuela viva llena de futuro}

La Escuela de Pensamiento Libre se estructura de la misma manera que una escuela tradicional, pero con las aportaciones innovadoras e inclusivas de nuestra 
manera de entender la educación de adultos en contextos donde residen, estudian o son atendidas personas con discapacidad.

En la Escuela de Pensamiento Libre hay "profesores" pero el 50\% del "claustro" aspiramos a que sean personas con discapacidad y que hayan "fracasado" en la escuela tradicional ajena al auténtico sentido de la inclusión educativa. Los profesores se denominan "maestros socráticos" y están formados en metodologías activas de aprendizaje. En cuanto a los "alumnos" de la Escuela tampoco son alumnos sino "aprendices de maestros socráticos" que, algunos de ellos, voluntariamente, a su vez formarán y educarán a otros. Esos alumnos tienen en su mayoría (mínimo el 80\%) un diagnóstico denominado "discapacidad intelectual." Para nosotros es solo eso, un diagnóstico porque la Escuela tratará de descubrir justo lo contrario: sus capacidades intelectuales.

En la Escuela de Pensamiento Libre hay "asignaturas" pero en estas asignaturas no se estudia nada, ni se enseña nada, ni existen exámenes, ni se ponen notas, si se mide el rendimiento. En la Escuela no se estudia lengua, ni mates, ni historia, ni plástica, ni idiomas etc. En realidad, no se estudia nada. El método inclusivo y narrativo de aprendizaje posibilita que el grupo de alumnos y maestros forme una "comunidad de aprendizaje y de diálogo" donde las ideas, las opiniones, las emociones y los valores de los participantes son los que conforman el currículum En este sentido, existen espacios educativos y un "horario" compuesto por asignaturas tales como: La clase de "pensamiento crítico", la clase de "educación emocional" o la clase de "ética" junto a las clases de "dinámicas de grupo" conforman esa jornada educativa de 8 horas diarias pudiendo ser horario intensivo $\mathrm{u}$ horario de mañana y tarde.

En la Escuela de Pensamiento Libre se evalúa a las personas y no a los alumnos y con este sistema de evaluación nadie es calificado y nadie recibe un número como nota. Cada persona con discapacidad trabaja en su "diario de pensamientos" y una entrevista personalizada con el tutor-maestro-facilitador del aprendizaje será la manera cualitativa de valorar sus potenciales que, en ningún caso, conlleva un informe negativo sino una vía abierta a seguir mejorando los hábitos que se tratan de ofrecer vía invitación. 
escuela de pensamiento libre. un viaje desde el estigma de la subnormalidad hasta el empoderamiento de personas entre personas

Todos los participantes al final de curso obtendrán el título de "Maestros Socráticos de la Escuela de Pensamiento Libre", a saber, seres humanos pensantes, dotados de razón y conciencia tal y como nos dice la Declaración de Derechos Humanos.

La "misión" de esos "alumnos" será, siempre desde la libertad, crear en sus centros o espacios cotidianos replicas de la Escuela donde cada uno de ellos recree la "experiencia de aprendizaje" que han tenido en la comunidad conversacional.

La Escuela de Pensamiento Libre pretende ser una institución escolar alternativa para la educación de personas adultas con discapacidad cuyo objetivo sea formar a personas que a su vez se conviertan en formadores de otras personas en sus contextos cotidianos. La Escuela nace con la vocación de ser una fuente donde las personas con discapacidad sientan que no solo son sujetos pasivos en el aprendizaje, sino que son personas capaces no solo de aprender sino de, con la metodología adecuada, ser parte del aprendizaje de otros. En el siglo XXI estamos en la denominada "sociedad del conocimiento" y el aprendizaje no se produce solo en una etapa de la vida, sino que es continuo y a lo largo de la vida. Las personas con discapacidad, por desgracia, no solo están excluidas de los sistemas educativos formales, sino que a veces la calidad de vida en cuestiones cognitivas se confunde con la instrucción y la enseñanza de las mismas materias y conocimientos en los que han fracasado como niños y jóvenes.

La manera de entender la educación de personas adultas con discapacidad, como venimos diciendo, nada tiene que ver con la transmisión de conocimientos sino con el aprendizaje de vivencia de valores humanos encarnados en el proyecto vital de cada persona.

Las posibilidades de la Escuela de Pensamiento Libre son ambiciosas ya que forman parte de un sueño y una utopía posible: la construcción de una sociedad más justa, igualitaria e inclusiva en la cual las personas con discapacidad coordinen cientos de "escuelas de pensamiento libre" diseminadas por todos los países, escuelas del "mundo al revés", a saber, escuelas donde las personas con discapacidad sean los que faciliten experiencias de aprendizaje a todo tipo de personas y de profesionales del mundo de la educación. 


\section{Declaración de Confianza del frontispicio de la Escuela.}

Al entrar en las instalaciones de la Escuela de Pensamiento Libre, unas letras de oro dicen lo siguiente:

1- Tú eres sabio

2. Tus preguntas son necesarias

3. Tú vas a ser escuchado/a

4. Eres un ser libre

5. Tú tienes la palabra y el silencio

6. Tú puedes expresar tus sentimientos

7. Tú eres un ciudadano de primera

8. Tú puedes soñar despierto

9. Tú puedes crecer lentamente

AQUII Y AHORA: TÚ ERES LO MÁS VALIOSO.

\section{Bibliografía}

CORTINA, Adela (2006). Ética de la razón cordial. Oviedo: Ediciones Nobel. ESQUIROL, Jean (2011). Tratado completo de las enajenaciones mentales. Valladolid: Editorial Maxtor.

FREIRE, Paulo (2002). Cartas a quien pretende enseñar. México: Siglo XXI Editores. FREIRE, Paulo (1990). La naturaleza política de la educación. Barcelona: Paidos. FREIRE, Paulo (2008). Pedagogía del oprimido. México: S. XXI Editores. KOHAN, Walter (2004). Infancia entre educación y filosofía. Barcelona: Laertes. MATE, Reyes (2013). La piedra desechada. Madrid: Trotta.

MATE, Reyes (2001). ¿Existe una responsabilidad histórica? Madrid: Instituto Cervantes.

REZOLA AMELIVIA, Rodolfo (2013). Filosofía y fragilidad. Barcelona: Laertes.

SAŃCHEZ ALCÓN. Chema (2010). Pensamiento Libre para personas con discapacidad intelectual. Madrid: Pirámide.

ORGANIZACIÓN MUNDIAL DE LA SALUD (2001). Clasificación internacional del funcionamiento, de la discapacidad y de la salud (CIF). Madrid: IMSERSO.

ORGANIZACIÓN DE NACIONES UNIDAS (2006). Convención de la ONU sobre los derechos de las personas con discapacidad. New York: ONU.

PINEL, Philippe. (1998). Tratado médico filosófico de la enajenación mental. Madrid: Nieva.

WEHMEYER Michael. “Autodeterminación y la tercera generación de prácticas de inclusión”, en Revista de educación, numero 349, 2009. 